\title{
Taxa de sudação e parâmetros histológicos de bovinos submetidos ao estresse calórico
}

\author{
[Sweat rate and histological parameters of cattle submitted to heat stress] \\ F. Ferreira ${ }^{1}$, W.E. Campos ${ }^{2 *}$, A.U. Carvalho ${ }^{2}$, M.F.A. Pires ${ }^{3}$, M.L. Martinez ${ }^{3}$, \\ M.V.G.B. Silva ${ }^{3}$, R.S. Verneque ${ }^{3}$, P.F. Silva ${ }^{4}$ \\ ${ }^{1}$ Aluno de pós-graduação - EV-UFMG - Belo Horizonte, MG \\ ${ }^{2}$ Escola de Veterinária - UFMG - Belo Horizonte, MG \\ ${ }^{3}$ Embrapa Gado de Leite - Juiz de Fora, MG \\ ${ }^{4}$ Bióloga autônoma
}

\begin{abstract}
RESUMO
Caracterizaram-se o pelame, a taxa de sudação e os parâmetros histológicos de 71 bovinos $F_{2}(1 / 2$ Gir x $1 / 2$ Holandês), 39 machos e 32 fêmeas, entre 14 e 20 meses de idade, submetidos a condições de termoneutralidade $\left(22^{\circ} \mathrm{C}\right.$ e $70 \%$ de umidade relativa - UR) e ao estresse calórico $\left(42^{\circ} \mathrm{C} \mathrm{e} 60 \%\right.$ UR). Os tratamentos foram realizados nas estações de verão e inverno em câmara bioclimática. $\mathrm{O}$ comprimento dos pelos e a espessura da capa foram maiores no inverno que no verão, sendo de 1,58 e 1,04cm e 5,31 e $3,91 \mathrm{~mm}$, respectivamente $(\mathrm{P}<0,05)$. A histologia da pele mostrou que, no verão, a área da glândula sudorípara e a distância da glândula ao epitélio foram menores que no inverno, sendo de 2589 e $4051 \mu \mathrm{m}$ e 294 e $344 \mu \mathrm{m}$, respectivamente $(\mathrm{P}<0,05)$. Concluiu-se que a estação do ano influencia as características de pelame, o posicionamento e a atividade das glândulas sudoríparas de forma a maximizar o controle da homeostase térmica.
\end{abstract}

Palavras-chave: bovino, bioclimatologia, histologia, pelame, sudorese

\begin{abstract}
Coat thickness, sweat rate, and histological parameters were characterized in 39 males and 32 females crossbred cattle (1/2 Holstein $x 1 / 2$ Gir), averaging 14 to 20 months of age, submitted to thermoneutrality $\left(22^{\circ} \mathrm{C}\right.$ and $70 \%$ of relative humidity - $\left.\mathrm{RH}\right)$ and heat stress $\left(42^{\circ} \mathrm{C}\right.$ and $\left.60 \% \mathrm{RH}\right)$ in summer and winter in a climatic chamber. Fur length and coat thickness were significantly higher in summer than winter, 1.58 and $1.04 \mathrm{~cm}$ and 5.31 and $3.91 \mathrm{~mm}$, respectively $(P<0.05)$. Skin histology showed that sweat gland area and distance of gland to epithelium was shorter in summer than in winter, 2,589 and 4,051 $\mu$ m and 294 and $344 \mu \mathrm{m}$, respectively $(P<0.05)$. It was concluded that the season influenced the coat thickness, the sweat glands disposal and activity to maximize thermic homeostasis control.
\end{abstract}

Keywords: cattle, bioclimatology, histology, coat thickness, sweaty

\section{INTRODUÇÃO}

Embora o reconhecimento dos efeitos prejudiciais do estresse calórico sobre o organismo animal tenha ocorrido no início do século, debates e questionamentos desses efeitos nas variáveis fisiológicas dos animais têm sido realizados até os dias atuais. O interesse dos pesquisadores em quantificar o estresse calórico bem como a forma apropriada para mensurar os limites fisiológicos da exposição dos animais ao estresse têm sido o motivo de vários estudos ao longo do tempo, com o objetivo de otimizar a resposta animal para que possa expressar seu potencial genético e apresentar uma melhor produção.

Quando a temperatura ambiente está acima da zona de conforto térmico, os animais entram em hipertermia e, concomitantemente, inicia-se o

Recebido em 6 de outubro de 2008

Aceito em 27 de março de 2009

*Autor para correspondência (corresponding author)

E-mail: wecampos2@yahoo.com.br 
aumento da perda de calor e/ou diminuição da produção de calor corporal, cuja eficiência depende de vários fatores, tais como, características anatômicas, morfológicas e fisiológicas. Estes podem resultar em maior ou menor capacidade dos animais em dissipar calor. Essa dissipação pode ocorrer por formas não evaporativas ou perda de calor sensível (condução, convecção e radiação) e perda por evaporação (pela pele ou pela respiração) (Cunningham, 1999).

Este trabalho ${ }^{1}$ teve como objetivo caracterizar respostas fisiológicas e histológicas de bovinos $\mathrm{F}_{2}(1 / 2$ Gir $\mathrm{x} 1 / 2$ Holandês $)$ submetidos ao estresse calórico.

\section{MATERIAL E MÉTODOS}

O trabalho foi realizado em câmara bioclimática no Campo Experimental Santa Mônica, pertencente à Embrapa Gado de Leite, localizado no distrito de Barão de Juparanã, município de Valença, Estado do Rio de Janeiro, situado a $22^{\circ} 21^{\prime}$ de latitude sul e $43^{\circ} 42^{\prime}$ de longitude oeste, a uma altitude média de $364 \mathrm{~m}$.

Foram utilizados 71 bovinos da geração $F_{2}(1 / 2$ Gir x $1 / 2$ Holandês) provenientes dos cruzamentos entre animais $F_{1}(1 / 2$ Holandês e $1 / 2$ Gir $)$ x $F_{1}(1 / 2$ Holandês e $1 / 2$ Gir), sendo 39 machos e 32 fêmeas, com idades entre 14 e 20 meses, pesos corporais entre 300 e $400 \mathrm{~kg}$, por período de 12 meses. Os animais permaneceram em piquetes de Brachiaria decumbens contendo cocho para sal mineral e água.

Nos dois períodos em que os animais permaneceram dentro da câmara bioclimática, não foram fornecidos água ou alimentos para reduzir seus efeitos sobre as respostas, sendo esse manejo repetido com intervalo de seis meses, focalizando-se as estações de verão (fevereiro, março e dezembro) e inverno (junho e julho).

As medidas da espessura da capa externa e do comprimento dos pelos foram realizadas na cernelha, entre o $12^{\circ}$ espaço intercostal nas

${ }^{1}$ Este trabalho fez parte do Projeto "Identificação de marcadores genéticos associados às características de resistência a endo e ectoparasitas e ao estresse térmico em bovinos" da Embrapa Gado de Leite. regiões superior e mediana do costado, com o auxílio de um paquímetro de precisão em ambiente externo à câmara climática.

Para caracterizar o ambiente térmico dentro da câmara durante $\mathrm{o}$ período experimental, a temperatura e a umidade relativa (UR) do ar foram registradas colocando-se termômetro de bulbo seco, de bulbo úmido e termômetro de globo negro em pontos distintos. O índice de temperatura e umidade (ITU) foi calculado de acordo com Kelly e Bond (1971).

$\mathrm{Na}$ tarde anterior ao dia do tratamento, os animais foram alocados na câmara bioclimática em condições de termoneutralidade $\left(22^{\circ} \mathrm{C}\right.$ e $70 \%$ UR), onde permaneceram por 12 horas. Após esse período, realizou-se a primeira coleta (antes do estresse). Posteriormente, os equipamentos eram ajustados para submeter os animais às condições de estresse calórico $\left(42^{\circ} \mathrm{C}\right.$ e $60 \%$ UR). Quando os termômetros atingiam os valores prédeterminados, iniciava-se a contagem do tempo para que os animais permanecessem por um período de seis horas. Após as seis horas de permanência, procedia-se à segunda coleta (após o estresse).

As amostras de tecido cutâneo foram obtidas no período da manhã, antes do tratamento. Após a administração de $2 \mathrm{~mL}$ de anestésico local distribuídos em pirâmide (Massone, 1999), foi retirada uma amostra de $0,1 \mathrm{~cm}$ de diâmetro do tecido cutâneo na região lateral direita na altura média do costado entre a $12^{\mathrm{a}}$ e $13^{\mathrm{a}}$ costelas de cada animal com o auxílio de um punch. A ferida foi selada com unguento Pearson (spray aerossol). As amostras foram coradas pela hematoxilina-eosina, sendo mensurados os perímetros de 10 glândulas sudoríparas, distância das glândulas ao epitélio e área do epitélio em aparelho computadorizado para morfometria no laboratório de análises de imagens do Departamento de Morfologia do Instituto de Ciências Biológicas da UFMG.

A taxa de sudação de todos os animais foi coletada no período da tarde pelo método de cloreto de cobalto desenvolvido por Berman e Morag (1971) e modificado por Schleger e Turner (1965). Esta variável foi mensurada com o auxílio de cronômetro digital e realizada sempre pelos mesmos examinadores. 
Para as análises de taxa de sudorese, de morfometria da glândula sudorípara e de características de pelame, foi usado o modelo $\mathrm{Y}_{\mathrm{ijk}}$ $=\mu+E_{i}+S_{j}+P_{k}+e_{i j k}$, em que: $Y_{i j k l m}$ é $a$ variável dependente; $\mu$ é a média geral; $\mathrm{E}$ é o efeito fixo de estação da medida ( $\mathrm{i}=$ verão, inverno $)_{\mathrm{i}} ; \mathrm{S}_{\mathrm{j}}$ é o efeito fixo de sexo do animal $(\mathrm{j}=$ macho, fêmea); $\mathrm{P}_{\mathrm{k}}$ é o efeito fixo de período $(\mathrm{k}=$ manhã, tarde); $\mathrm{e}_{\mathrm{ijk}}$ é o erro associado a cada observação com $\sim \mathrm{N}\left(0, \sigma^{2}\right)$.

Para as análises de correlação entre as variáveis paramétricas, usou-se método de Pearson (Sampaio, 2002). As diferenças entre as médias dos tratamentos propostos foram comparadas adotando-se 5\% de significância. Os resultados foram obtidos utilizando-se o programa SAS/1988.

\section{RESULTADOS E DISCUSSÃO}

As condições ambientais permaneceram constantes dentro da câmara bioclimática no verão e no inverno, e as temperaturas médias obtidas com os termômetros de bulbo seco, bulbo úmido e globo negro no período da manhã, tanto no verão quanto no inverno, foram de $22,18 \mathrm{e}$ $23^{\circ} \mathrm{C}$, respectivamente, com ITU igual a 69 , mostrando que os animais permaneceram dentro da faixa de conforto térmico. No período da tarde, esses valores médios apresentaram elevação significativa; 43,36 e $44^{\circ} \mathrm{C}$ para os termômetros de bulbo seco, bulbo úmido e globo negro, respectivamente, e ITU igual a 97, expondo os animais a condições de estresse calórico severo.
A temperatura do ar na câmara climatizada, $43^{\circ} \mathrm{C}$, no período da tarde, esteve muito acima da temperatura crítica superior para bovinos, $25^{\circ} \mathrm{C}$, índice que representa, de modo geral, uma condição de emergência para os animais (Silva, 2000). As médias de temperatura e umidade para os períodos de verão e inverno foram de $23,2^{\circ} \mathrm{C} \mathrm{e}$ $69,8 \%$ e $18,6^{\circ} \mathrm{C}$ e $71,9 \%$ respectivamente.

A temperatura retal (TR) no período da manhã ficou dentro da faixa de normalidade para bovinos tanto no verão quanto no inverno $(\mathrm{P}>0,05)$, apresentando média entre as estações de $38,02^{\circ} \mathrm{C}( \pm 0,05)$. Entretanto, no período da tarde, a TR foi maior $(\mathrm{P}<0,05)$, sendo tais valores superiores aos do limite fisiológico, sugerindo que esses animais não conseguiram manter a homeotermia. $\mathrm{O}$ armazenamento de calor pelo aumento da temperatura corporal da manhã para a tarde provocou hipertermia nos bovinos estressados tanto no inverno, $40,59^{\circ} \mathrm{C}$, quanto no verão, $41,14^{\circ} \mathrm{C}(\mathrm{P}<0,05)$.

$\mathrm{Na}$ Tab. 1, encontram-se os resultados relacionados à avaliação histológica do fragmento do tecido cutâneo. Ao se comparar as estações, verificou-se que as áreas das glândulas sudoríparas apresentaram-se menores na época do verão $(\mathrm{P}<0,05)$. Estes resultados confirmaram os de Benjamin (1971), citado por Bhayani e Vyas (1990), que observou volume aumentado das glândulas sudoríparas no período do inverno em relação ao verão. O menor volume das glândulas sudoríparas indica o pico funcional delas, com aumento do volume no período do inverno, o que indica sua inatividade.

Tabela 1. Área das glândulas sudoríparas $\left(\mu \mathrm{m}^{2}\right)$, distância das glândulas sudoríparas ao epitélio $(\mu \mathrm{m})$ e área do epitélio $\left(\mu \mathrm{m}^{2}\right)$ da pele de bovinos nas estações do inverno e do verão

\begin{tabular}{lccc}
\hline & $\begin{array}{c}\text { Área da glândula } \\
\text { sudorípara }\left(\mu \mathrm{m}^{2}\right)\end{array}$ & $\begin{array}{c}\text { Distância da glândula } \\
\text { ao epitélio }(\mu \mathrm{m})\end{array}$ & $\begin{array}{c}\text { Área do } \\
\text { epitélio }\left(\mu \mathrm{m}^{2}\right)\end{array}$ \\
\hline Média+EPM & Média+EPM & Média+EPM \\
\hline Verão & $4.051,48+151,41 \mathrm{a}$ & $344,16+8,40 \mathrm{a}$ & $109.278,43 \pm 4.964,67$ \\
& $2.589,70 \pm 142,59 \mathrm{~b}$ & $294,65 \pm 7,91 \mathrm{~b}$ & $104.486,86 \pm 4.675,66$ \\
\hline $\mathrm{CV}=33,27$ & $\mathrm{CV}=19,19$ & $\mathrm{CV}=33,74$ \\
$\mathrm{R} 2=0,73$ & $\mathrm{R} 2=0,65$ & $\mathrm{R} 2=0,50$
\end{tabular}

Médias seguidas por letras diferentes na mesma coluna diferem entre si $(\mathrm{P}<0,05)$.

EPM: erro-padrão da média.

As glândulas sudoríparas encontram-se localizadas mais superficialmente no verão e mais profundas na época de inverno $(\mathrm{P}<0,05)$. A menor profundidade das glândulas também é indicativo do aumento de atividade funcional. Mugale e Bhosle (2002), ao estudarem as 
diferenças de profundidade das glândulas sudoríparas em bovinos, observaram que, no verão, elas localizaram mais superficialmente e atribuíram tal achado à maior atividade delas no verão, indicando que a atividade de sudação é mais intensa nessa época do ano.

Os resultados para as características de espessura da capa e o comprimento dos pelos podem ser vistos na Tab. 2. As médias dos valores dessas características foram maiores na estação do inverno. As médias gerais dos valores da espessura da capa observadas foram de $3,91 \mathrm{~mm}$ e $5,31 \mathrm{~mm} \quad(\mathrm{P}<0,05)$ e, em relação ao comprimento dos pelos, foram de $1,04 \mathrm{~cm} \mathrm{e}$
$1,58 \mathrm{~cm} \quad(\mathrm{P}<0,05)$, no verão e no inverno, respectivamente. Valores menores dessas características na estação do verão são adequados, pois pelames menos densos e mais curtos favorecem a termólise, pois, quanto maior a espessura da capa e o comprimento dos pelos, maior será o isolamento térmico, que pode prejudicar a dissipação de calor. A variação na espessura da capa e no comprimento dos pelos observada nas estações do ano também foi verificada por outros autores. Semelhantemente, Arantes Neto (1985) e Silva (1998) relataram valores de espessura da capa e do comprimento dos pelos maiores no inverno do que no verão.

Tabela 2. Espessura da capa $(\mathrm{mm})$, comprimento dos pelos $(\mathrm{cm})$ e taxa de sudação $\left(\mathrm{g} / \mathrm{m}^{2} / \mathrm{h}\right)$ de bovinos nas estações do inverno e do verão (Média \pm EPM)

\begin{tabular}{|c|c|c|c|}
\hline \multicolumn{4}{|c|}{ Espessura da capa } \\
\hline & Macho & Fêmea & Média \\
\hline Inverno & $5,81 \pm 0,20 \mathrm{aA}$ & $4,81 \pm 0,23 \mathrm{aB}$ & $5,31 \pm 0,15$ \\
\hline Verão & $3,93 \pm 0,20 b$ & $3,89 \pm 0,23 b$ & $3,91 \pm 0,15$ \\
\hline Média & $4,88 \pm 0,15 \mathrm{~A}$ & $4,35 \pm 0,16 \mathrm{~B}$ & $\mathrm{CV}=27,66 \quad \mathrm{R} 2=0,58$ \\
\hline \multicolumn{4}{|c|}{ Comprimento dos pelos } \\
\hline & Macho & Fêmea & Média \\
\hline Inverno & $1,56 \pm 0,06 a$ & $1,60 \pm 0,07 \mathrm{a}$ & $1,58 \pm 0,04$ \\
\hline Verão & $1,01 \pm 0,07 b$ & $1,08 \pm 0,07 b$ & $1,04 \pm 0,04$ \\
\hline Média & $1,29 \pm 0,04$ & $1,34+0,05$ & $\mathrm{CV}=30,54 \mathrm{R} 2=0,72$ \\
\hline \multicolumn{4}{|c|}{ Taxa de sudação } \\
\hline & Macho & Fêmea & Média \\
\hline Inverno & $224,54+15,94$ & $220,65 \pm 19,33$ & $222,60+12,53$ \\
\hline Verão & $265,52+15,94$ & $213,32+17,60$ & $239,42 \pm 11,87$ \\
\hline Média & $245,03 \pm 11,27$ & $216,98+13,07$ & $\mathrm{CV}=42,50 \quad \mathrm{R} 2=0,60$ \\
\hline
\end{tabular}

Médias seguidas por letras diferentes minúsculas na coluna ou maiúsculas na linha diferem entre si $(\mathrm{P}<0,05)$. EPM: erro-padrão da média.

Observou-se correlação positiva ( $\mathrm{r}=0,28$; $\mathrm{P}<0,001)$ entre espessura da capa e comprimento dos pelos, evidenciando que os diversos mecanismos fisiológicos envolvidos na homeotermia ocorrem simultaneamente. Mesmo que tenha ocorrido diferença de temperatura no período da tarde entre as estações, taxas similares de sudação foram observadas.

Na Tab. 2, pode ser vista a taxa de sudação dos animais. Na câmara bioclimática, a taxa de sudação média foi de $222,60 \mathrm{~g} / \mathrm{m}^{2} / \mathrm{h}$ na estação do inverno e $239,42 \mathrm{~g} / \mathrm{m}^{2} / \mathrm{h}$ no verão, isto é, houve igualdade $(\mathrm{P}>0,05)$ entre as estações. Da mesma forma, ao trabalhar com câmara bioclimática, Azevedo (2004) não observou diferença para a taxa de sudação entre as estações de verão e inverno, em vacas mestiças Holandês-Zebu, na região de Coronel Pacheco, MG.

As médias encontradas foram mais altas que as relatadas na literatura (Azevedo, 2004; Scharf et al., 2008) e confirmam o fato de os animais estarem em estresse calórico, e que, sob temperaturas elevadas, há aumento da sudorese, na tentativa de evitar a hipertermia. Essa diferença ocorreu, provavelmente, devido ao valor alto da temperatura dentro da câmara bioclimática no período da tarde, que foi superior às temperaturas encontradas pelos autores citados. Shearer e Beede (1990) constataram que, em bovinos, a sudorese é mais importante que a 
respiração, a partir de $21^{\circ} \mathrm{C}$. A menor utilização da frequência respiratória (FR) para perder calor é uma estratégia energética que torna a vida para bovinos nos trópicos menos dispendiosa e mais confortável. Isso reforça a necessidade de se criar sombra nos pastos destinados à criação extensiva de bovinos ou ajustar a temperatura ambiente para animais confinados.

Em geral, animais que apresentam maior capacidade de sudação utilizam menos a FR para dissipar calor (Azevedo, 2004). A relação inversa entre a sudorese e a capacidade de ofegar, citada por Bianca (1965) no Zebu, foi observada no presente trabalho, visto que os animais que apresentaram maior taxa de sudação mostraram menor FR, fato já observado por Ferreira et al. (2006), pois a correlação entre essas variáveis foi negativa e significativa $(\mathrm{r}=-0,17 ; \mathrm{P}<0,05)$.

A capacidade do organismo de perder calor para o ambiente depende da secreção e da evaporação do suor. À medida que a temperatura corporal aumenta, a sudorese também aumenta para evitar o acúmulo excessivo de calor no organismo. As temperaturas ambientes estressantes podem ocasionar perdas hídricas pela sudorese e pelo ofego. Estas perdas hídricas, quando não repostas adequadamente, podem levar à desidratação e essa resulta em dificuldade na regulação da temperatura corporal, o que pode causar redução no desempenho. Além disso, a capacidade termorregulatória insuficiente num ambiente quente e úmido representa risco para a homeostase, levando à hipertermia que causa uma série de distúrbios relacionados com o calor, constituindo-se uma situação potencialmente fatal.

\section{CONCLUSÕES}

A estação do ano influenciou as características de pelame, o posicionamento e a atividade das glândulas sudoríparas de forma a maximizar o controle da homeostase térmica.

\section{REFERÊNCIAS BIBLIOGRÁFICAS}

ARANTES NETO, J.G. Aspectos genéticos da variação de algumas características da pele e do pelame em gado Jersey. 1985. 58f. Dissertação (Mestrado) - Faculdade de Ciências Agrárias e Veterinárias, Universidade Estadual Paulista, Jaboticabal, SP.
AZEVEDO, M. Efeitos do verão e do inverno sobre os parâmetros fisiológicos de vacas mestiças Holandês-Zebu, em lactação, na região de Coronel Pacheco, MG. 2004. 85f. Tese (Doutorado) Escola de Veterinária, Universidade Federal de Minas Gerais, Belo Horizonte, MG.

BENJAMIN, M.M. Fluid and eletrolytes. Outline of veterinary clinical pathology. Ames: Iowa State University, 1981.12p.

BERMAN, A.; MORAG, M. Nychthemeral patterns of thermoregulation in high-yielding dairy cows in a hot dry near-natural climate. Aust. J. Agric. Res., v.22, p.671-680, 1971.

BHAYANI, D.M.; VYAS, K.N. Regional differences in the sweat gland characteristics in Gir cattle with reference to thermoregulation. Indian J. Anim. Sci., v.60, p.817-820, 1990.

BIANCA, W. Reviews of the progress of dairy science. Section A. Physiology. Cattle in a hot environmental. J. Dairy Res., v.32, p.291-345, 1965.

CUNNINGHAM, J.G. Tratado de fisiologia veterinária. 2.ed. Rio de Janeiro: Guanabara Koogan, 1999. 454p.

FERREIRA, F.; PIRES, M.F.A.; MARTINEZ, M.L. et al. Parâmetros fisiológicos de bovinos cruzados submetidos ao estresse calórico. Arq. Bras. Med. Vet. Zootec., v.58, p.732-738, 2006.

KELLY, C.F.; BOND, T.E. Bioclimatic factors and their measurements. In: A GUIDE to environmental research on animals. Washington: National Academic of Sciences, 1971. p.71-92.

MASSONE, F. Anestesiologia veterinária: farmacologia e técnicas. 3.ed. Rio de Janeiro: Guanabara Koogan, 1999. 225p.

MUGALE, R.R.; BHOSLE, N.S. Effect of age, sex and season on the sweat gland density and depth in Deoni cattle. Indian Vet. J., v.79, p.157-159, 2002.

SAMPAIO, I.B.M. Estatística aplicada à experimentação animal. Belo Horizonte: FEPMVZ, 2002. 265p.

SCHARF, B.; WAX, L.E.; AIKEN, G.E. et al. Regional difference in sweat rate response of steers to short-term heat stress. Int. J. Biometeorol., v.52, p.725-73, 2008.

SCHLEGER, A.; TURNER, H.G. Swetting rates of cattle in field and their reaction to diurnal and seasonal changes. Aust. J. Agric. Res., v.16, p.92106, 1965. 
SHEARER, J.K.; BEEDE, D.K. Thermoregulation and physiological responses of dairy cattle in hot weather. Heat stress. Part 1. Agri-Pract., v.11, p.517,1990 .

SILVA, I.J.O. Climatização das instalações para bovino leiteiro. In: SIMPÓSIO BRASILEIRO DE
AMBIÊNCIA NA PRODUÇÃO DE LEITE, Piracicaba, 1998. Anais... Piracicaba: FEALQ, 1998. p.114-145.

SILVA, R.G. Introdução à bioclimatologia animal. São Paulo: Nobel, 2000. 286p. 